\title{
Ecologically realistic modalities in arthropod supercooling point distributions
}

\author{
Timothy C. HAWES ${ }^{1}$, Jeffrey S. BALE ${ }^{1}$, Peter CONVEY ${ }^{2}$ and Roger WORLAND ${ }^{2}$ \\ ${ }^{1}$ Department of Biosciences, University of Birmingham, Edgbaston, Birmingham B15 2TT, UK; e-mail: tinstone12@hotmail.com \\ ${ }^{2}$ British Antarctic Survey, High Cross, Madingley Road, Cambridge CB3 OET, UK
}

Key words. Cold hardiness, supercooling point, categories of cold hardiness, bimodality

\begin{abstract}
Modality in the supercooling points of cold tolerant but freezing intolerant terrestrial arthropods has proved a pragmatically reliable means of distinguishing between summer and winter cold hardiness in such species. This paper proposes an ecologically realistic method of modal analysis which may either be used in lieu of the traditional separation of supercooling points into "high" and "low" groups, or as a complementary assessment of the risk of freezing mortality. Instead of a posteriori determinations of modal break points, animal supercooling points are assigned a priori to one of four categories of cold hardiness: (1) summer coldhardy; (2) semi-cold-hardy; (3) cold-hardy; and (4) winter cold-hardy. Each category is identified by the temperature range within which arthropods can be expected to freeze. The temperature ranges assigned to each category are based on a conservative, but realistic, assessment of the temperatures at which animals can be expected to freeze at a given point in the season. The approach has greater discriminatory power than traditional bimodal descriptors (i.e."summer" and "winter" cold-hardy), as well as allowing animal supercooling points to be related to the temperatures they actually experience in their habitats. Thus, for example, animals considered "summer" cold-hardy according to conventional analysis may actually be "semi-cold-hardy" with supercooling points well within the safety margin of minimum ambient temperatures.
\end{abstract}

\section{INTRODUCTION}

Building on the earlier work of Bachmetjev in 1901, Robinson in 1927 and Payne in 1926 (Sømme, 2000), R.W. Salt $(1936,1950,1961)$ made popular the use of the exotherm or latent heat released by a cooled animal at the temperature of its crystallisation $\left(\mathrm{T}_{\mathrm{c}}\right)$ as a measure of insect cold hardiness. Although the potential for prefreeze mortality was recognised by Colhoun (1960) and Salt (1961), supercooling points (SCPs) became the primary assay used to assess an organism's cold hardiness. Subsequently the importance of distinguishing between SCPs and the lower lethal temperatures of animals - i.e. the occurrence of cold injury and pre-freeze mortality was demonstrated (Bale, 1987, 1993, 1996). SCPs however, still have relevance to studies on freeze tolerant animals (for which the SCP is a reflection of the way in which they manage internal ice nucleation) and for the small but important class of arthropods that do not experience significant pre-freeze mortality.

The measurement of SCPs has, in particular, continued to have relevance for polar terrestrial invertebrates, for many of which - technically "highly chill-tolerant" (sensu Bale, 1993) - the supercooling point is, except sometimes in case of extended subzero exposure (Convey \& Worland, 2000), a good proxy for the lower lethal temperature (e.g. Sinclair et al., 2006). This paper discusses the conventional modal analysis of SCP distributions and suggests a revised method for discriminating between levels of cold hardiness in arthropod populations that relates mortality at $T_{c}$ to environmental temperatures. Examples and discussion are based around polar invertebrates, but are equally applicable to other studies where the SCP is a useful measure of mortality. The issues raised here are however, of less relevance to freeze tolerant invertebrates which, unless they are significantly stressed (e.g. Bale et al., 2001; Brown et al., 2004), do not show significant variability in SCPs (Addo-Bediako et al., 2000).

Decisions of modal division of SCPs have traditionally been based on a binary model of cold hardiness with animals conceived as being either summer- or winteracclimated/acclimatized (e.g. Block \& Sømme, 1982; Sømme \& Block, 1982; Cannon \& Block, 1988; Worland \& Convey, 2001; Sinclair et al., 2003). This binary model underlies the interpretation of all of the modal distributions observed in polar terrestrial arthropods. Thus unimodal distributions (e.g. Block \& Sømme, 1982; Worland \& Convey, 2001; Sinclair et al., 2003) are seen to represent either summer or winter levels of cold hardiness; bimodal distributions (e.g. Worland \& Convey, 2001; Sinclair et al., 2003) the relative proportion of animals in either group, and trimodal distributions (e.g. Sinclair et al., 2003) show both levels of cold hardiness with the middle modality reflecting stochastic variability (Fig. 1).

Numerous factors affecting SCP distributions in Antarctic terrestrial arthropods have been examined including seasonal and diurnal temperature (e.g. Young \& Block, 1980; Convey \& Worland, 2000; Worland \& Convey, 2001; Sinclair et al., 2003), cooling rate (e.g. Cannon, 1983), desiccation (e.g. Worland \& Block, 2003), external nucleators (e.g. Convey \& Worland, 2000) diet (e.g. Worland \& Lukešová, 2000) and moulting (e.g. Worland, 2005; Hawes et al., in press a). However, even for the most studied of these animals, the collembolan Cryptopygus antarcticus, the shifts between high and low freezing point distributions remain unexplained in mechanistic terms. 
In terms of identifying the ways arthropods manage ice nucleation at seasonal scales, the binary model of cold hardiness is a useful means of interrogating the cues and mechanisms (e.g. gut evacuation, cryoprotectants) responsible for changes in SCPs. This is particularly appropriate for $C$. antarcticus, which is the model organism for this approach and for which bimodal distributions are relatively clear-cut - at least at seasonal scales. However, although some species do indeed appear to conform to such strictly seasonally delineated patterns of cold hardiness [e.g. the high Arctic collembolan, Hypogastrura tullbergi (Schäffer) (Hawes et al., in press b)], the extension of investigations to other species and other experimental regimes have shown that the "model" response is far from universal in polar terrestrial arthropods.

Other polar species frequently demonstrate less clear-cut patterns (e.g. Sinclair et al., 2003) or evidence of transitional SCPs within a general pattern of bimodality (e.g. the mite Halozetes belgicae, see below). Moreover, as a means of assessing low temperature survival within an ecological context, this kind of modality analysis may not have sufficient resolution to accurately determine the likelihood of cold-induced mortality. Thus, although it may be tacitly acknowledged among investigators that "summer" cold hardy animals can survive some sub-zero temperatures, the proportions of "summer" animals that freeze at temperatures below seasonal or daily minimum habitat temperatures has received little attention. This question is particularly pertinent to recent investigations into summer cryoprotection in the Antarctic (Worland \& Convey, 2001; Sinclair et al., 2003).

Additional discrimination may also be needed to distinguish the cold hardiness of overwintering animals from those where freezing point distributions have been shifted to the "low group" at the beginning of winter or through low temperature acclimation. True winter levels of cold hardiness of polar arthropods have rarely been measured for obvious logistic reasons (with laboratory acclimations employed as surrogates) (but see Coulson et al., 2000, for population level studies), but there is a suggestion that some overwintering animals (e.g. species from Continental Antarctica and $H$. belgicae) - with their full complement of cryoprotective measures in place - may have even lower SCPs that those observed in typical "low groups". Cannon \& Schenker (1985), for example found $H$. belgicae exposed to subzero temperatures for extended periods had a minimum SCP of $-38^{\circ} \mathrm{C}$ which is considerably lower than the SCPs of "winter-acclimatized" mites (minimum SCP c. $-32^{\circ} \mathrm{C}$ ) sampled in the summer at Rothera Research Station, on the Antarctic peninsula (unpubl. data). While, Pryor (1962) reported Isotoma klovstadi to be capable of surviving temperatures below $-50^{\circ} \mathrm{C}$.

Regression lines or curves of best-fit may be poor descriptors of lower lethal limits (LLTs) as the multimodal character of many SCP distributions suggests that mortality in a sample distribution is often a distinctly nonlinear phenomenon. Rothery \& Block (1992) for example, found that only "low groups" truly conformed to an exponential model based on freezing water droplets. Thus although medians represent the most useful summary statistic of cold tolerance in a multi-modal sample, analysis and discrimination of such modes provides a way of investigating the variability within a sample (or samples) and, ultimately, through experimental manipulation, the factors responsible for such variability (e.g. acclimation, acclimatization, feeding state, moult state). Here, we propose a simple categorical approach to mortality risk assessment that has the advantages of: (1) being applicable to any species or modal distribution; (2) preserves the non-linear, modal character of SCPs; and (c) can be applied to the large published literature on SCP variation in polar terrestrial arthropods. Sinclair et al. (2006) have used SCP data to model the likelihood of 5\% of Continental Antarctic collembolans freezing at given microhabitat temperatures. The approach described in this analysis employs the same rationale - the belief that SCPs should be analysed in tandem with environmental temperatures (see also Turnock \& Fields, 2005) - although here the aim is to arrive at a reliable, but conservative, assessment of the proportion of animals likely to be at risk from given microhabitat temperatures.

To illustrate this approach and demonstrate its relevance to assessments of the risk of summer freeze mortality, we analyse snap-shot summer SCP distributions of adults of 5 Maritime Antarctic micro-arthropods: Cryptopygus antarcticus (Willem), Friesia grisea (Schäffer), Alaskozetes antarcticus (Michael), Halozetes belgicae (Michael), and Stereotydeus villosus (Trouessart).

\section{MATERIAL AND METHODS}

\section{Sampling and experimental protocol}

Investigations were carried out from December 2004 to March 2005 at the British Antarctic Survey research station at Rothera Point, Adelaide Island, on the west coast of the Antarctic Peninsula (Maritime Antarctic) $\left(67^{\circ} 34^{\prime} \mathrm{S}, 66^{\circ} 08^{\prime} \mathrm{W}\right)$. Animals were collected from rocks and moss at nearby Lagoon Island and either acclimated for varying periods of time at $5^{\circ} \mathrm{C}$ or their SCPs were determined within a few hours of collection. SCPs were determined using differential scanning calorimetry (DSC) (Block, 1994).

\section{Ecologically realistic modal analysis}

Modality in a sample distribution is an expression of sample variability. Although frequently noted, it is rarely analysed in a biological context (Zar, 1999). SCP distributions - for which such variability may reflect stochasticity and/or the relative degree of cold hardening in a sample population - are however, a notable exception. Traditional forms of SCP modal analysis (e.g. Powell, 1976; Rothery \& Block, 1992; Worland \& Convey 2001; Sinclair et al., 2003) have concentrated on the frequency modes of SCP distributions. Thus distributions are divided into low (freezing below a certain temperature) and high (freezing above a certain temperature) modal groups on a species-specific basis, with break-points ranging from -15 to $-24^{\circ} \mathrm{C}$ (Cannon \& Block, 1988).

The method outlined here places its primary emphasis on ecologically defined modes (that are equivalent to biologically significant thermal thresholds). The consequence of this is that although there may be only one or two frequency modes in an 

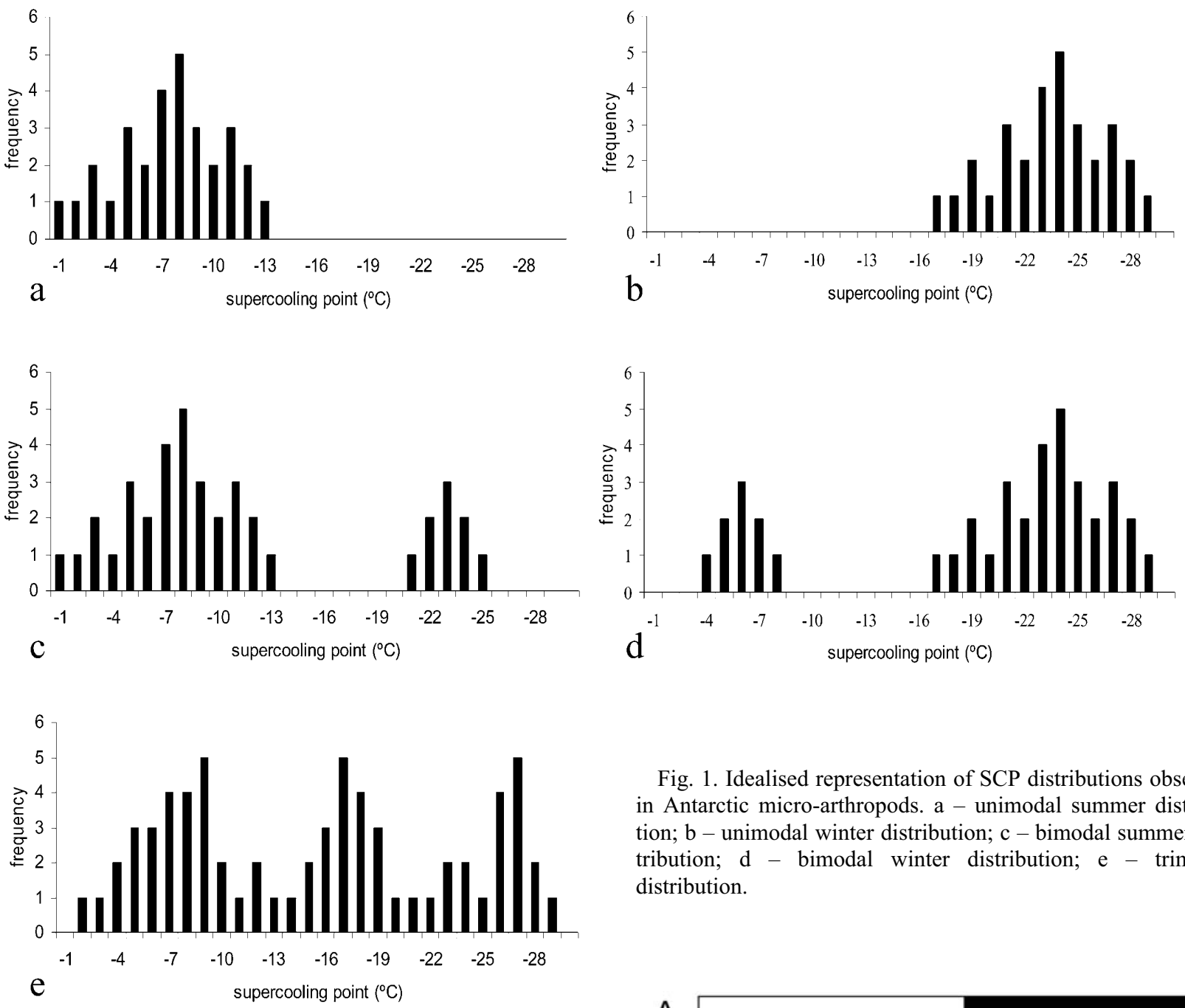

Fig. 1. Idealised representation of SCP distributions observed in Antarctic micro-arthropods. a - unimodal summer distribution; $\mathrm{b}$ - unimodal winter distribution; $\mathrm{c}$ - bimodal summer distribution; d - bimodal winter distribution; e - trimodal distribution.

SCP distribution, there will always be three or four (depending on thresholds used, see below) ecological modes. In other words, the method recognizes both potential and actual modalities. For, although the variability of a sample (and therefore its modalities) may not be constant, the ecological context of these modalities (low temperature survival) is constant.

The approach is based on assigning a priori four levels of low temperature capability to Antarctic arthropods: summer cold hardy, semi-cold-hardy, cold-hardy, and winter cold-hardy. Summer cold-hardy refers to animals that will freeze at high sub-zero temperatures $\left(0\right.$ to $\left.-10^{\circ} \mathrm{C}\right)$; semi-cold-hardy animals will freeze at intermediate low temperatures $\left(-10\right.$ to $\left.-20^{\circ} \mathrm{C}\right)$; cold-hardy animals are capable of surviving winter temperatures in their microhabitats $\left(-20\right.$ to $\left.-30^{\circ} \mathrm{C}\right)$; and winter cold-hardy animals are those that can survive at temperatures below $-30^{\circ} \mathrm{C}$ (but see below). Fig. 2 provides a schematic comparison of these a priori categories with those of traditional modal analysis. Note, in particular that the "semi-cold hardy" state coincides with the tails (right and left, respectively) of the "summer" and "winter" distributions (Fig. 1). This is the "safe zone" for summer arthropods - which, although rarely apparent as a distinct mode in terms of SCP frequencies (but see $F$. grisea in Sinclair et al., 2003), represents a low temperature capability sufficient to withstand summer minimum temperatures.

The temperature ranges chosen for modal discrimination are based on a conservative interpretation of microhabitat temperatures in the Maritime Antarctic (Fig. 3) with $-10^{\circ} \mathrm{C}$ and $-20^{\circ} \mathrm{C}$

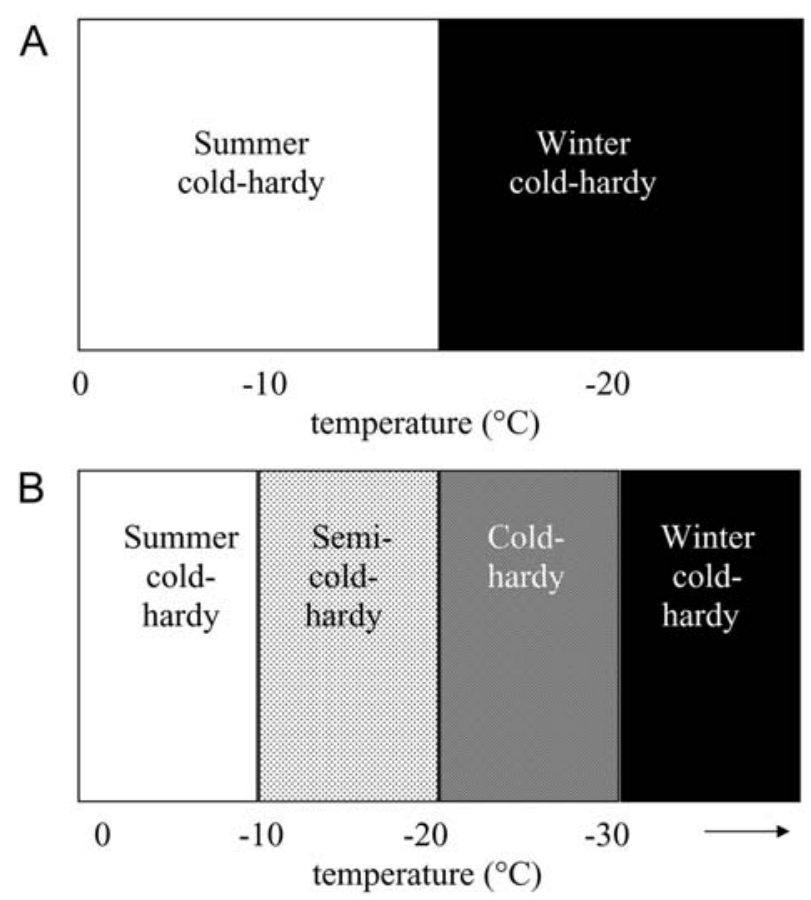

Fig. 2. Schematic comparison of (A) traditional division of SCPs in Antarctic terrestrial arthropods as either summer or winter cold-hardy and (B) ecologically realistic modal division of arthropod SCPs. 

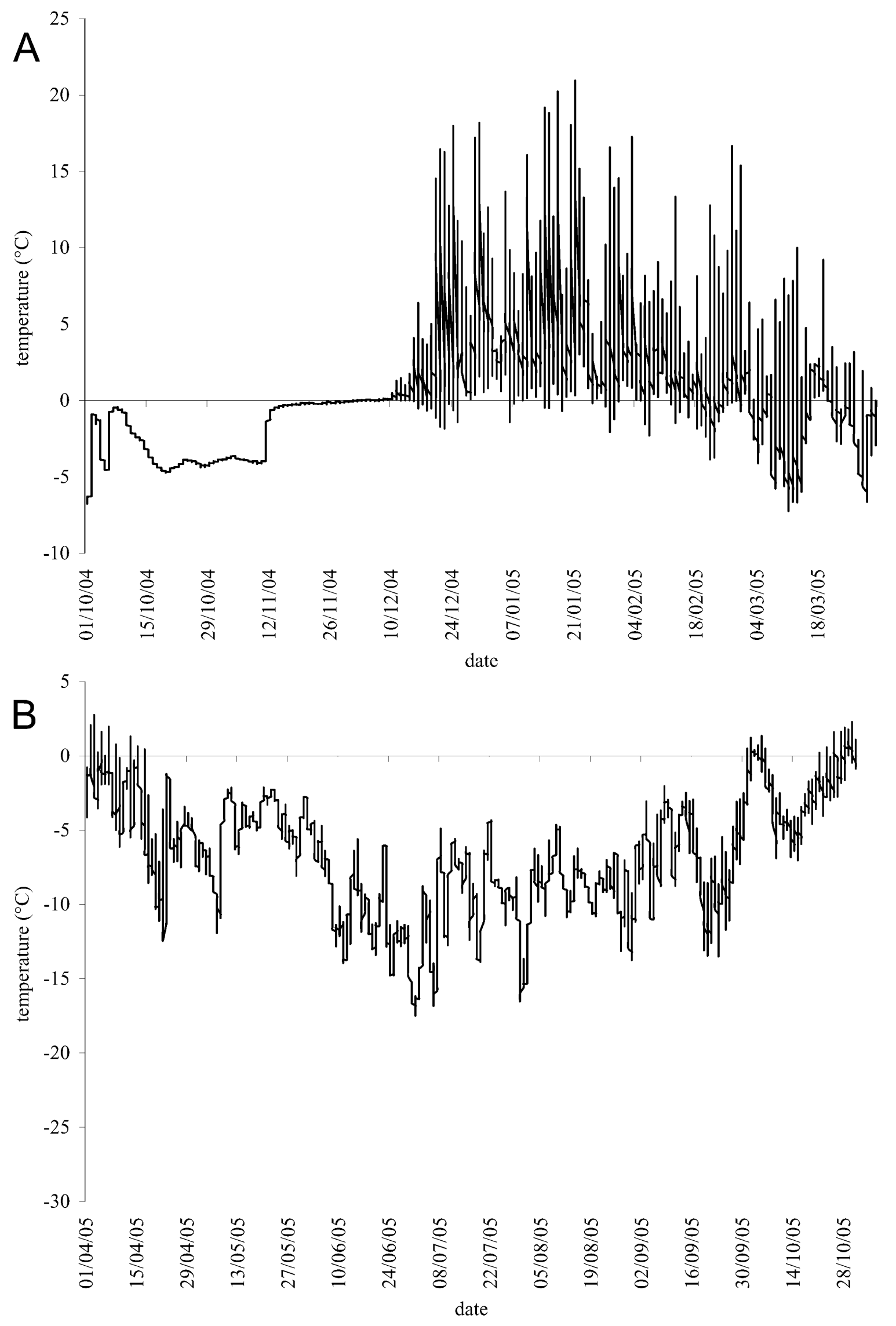

Fig. 3. Temperatures at the soil surface on Anchorage Island, Marguerite Bay through 2004-5: A - austral summer; B - austral winter (data from Anchorage micro-met station, British Antarctic Survey, Biological Sciences Division). 
TABLE 1. Comparison of modalities in SCP distributions from 5 Antarctic micro-arthropods using traditional and ecologically realistic modal analysis.

\begin{tabular}{|c|c|c|c|c|c|c|c|}
\hline \multirow{2}{*}{ Species } & \multirow{2}{*}{ Acclimation treatment* } & \multirow{2}{*}{$\mathrm{n}$} & \multirow{2}{*}{$\begin{array}{c}\begin{array}{c}\text { Traditional } \\
\text { modal division }\end{array} \\
\text { HG : LG ratio** }\end{array}$} & \multicolumn{4}{|c|}{ Ecologically realistic modal division (n) } \\
\hline & & & & $\begin{array}{l}\text { Summer-cold } \\
\text { hardy }\end{array}$ & $\begin{array}{l}\text { Semi-cold } \\
\text { hardy }\end{array}$ & $\begin{array}{l}\text { Cold } \\
\text { hardy }\end{array}$ & $\begin{array}{l}\text { Winter- } \\
\text { cold hardy }\end{array}$ \\
\hline \multicolumn{8}{|l|}{ Collembola } \\
\hline \multirow[t]{2}{*}{ Cryptopygus antarcticus } & $5^{\circ} \mathrm{C} 21$ days on sieved moss & 100 & $99: 1$ & 98 & 2 & 0 & 0 \\
\hline & $F(3 / 3 / 05)$ from moss & 128 & $33: 31$ & 60 & 16 & 52 & 0 \\
\hline Friesia grisea & $\mathrm{F}(5 / 2 / 05)$ from under rocks & 20 & $13: 7$ & 8 & 8 & 4 & 0 \\
\hline \multicolumn{8}{|l|}{ ACARI } \\
\hline Alaskozetes antarcticus & $\mathrm{F}(7 / 2 / 05)$ & 18 & $5: 4$ & 10 & 1 & 7 & 0 \\
\hline \multirow[t]{2}{*}{ Halozetes belgicae } & $\begin{array}{l}\mathrm{F}(5 / 2 / 05) \text { from lichen- } \\
\text { encrusted stones }\end{array}$ & 23 & $17: 6$ & 5 & 12 & 6 & 0 \\
\hline & $\begin{array}{l}\text { F }(28 / 3 / 05) \text { from lichen- } \\
\text { encrusted stones }\end{array}$ & 27 & $1: 8$ & 1 & 2 & 5 & 19 \\
\hline Stereotydeus villosus & $5^{\circ} \mathrm{C} 7$ days on moss & 18 & $17: 1$ & 12 & 6 & 0 & 0 \\
\hline
\end{tabular}

$* \mathrm{~F}=$ field-fresh; $* * \mathrm{HG}=$ high group; $\mathrm{LG}=$ low group. Division points between low and high groups: C. antarcticus; A. antarcticus $=-15^{\circ} \mathrm{C}$ (Worland \& Convey, 2001); Halozetes belgicae $=-20^{\circ} \mathrm{C}\left(\right.$ Cannon \& Schenker, 1985); S. villosus $=-15^{\circ} \mathrm{C}$; in agreement with Sinclair et al. (2003) we found no obvious division between high and low groups for $F$. grisea; so $-15^{\circ} \mathrm{C}$ is used as a conservative (i.e. likely to underestimate the size of the high group) breakpoint to allow comparison.

set as conservative thresholds for minimum temperatures during the summer and winter respectively. Habitat temperatures will of course vary at micro-, meso- and macro-scales with latitude and exposure. However, although the exact temperatures ranges at which each of these categories is assigned may vary, preliminary inspection of published microclimate data on colder continental Antarctic terrestrial habitats (e.g. Sinclair et al., 2006) suggests that the most potentially controversial of these - the assignment of $-10^{\circ} \mathrm{C}$ as the break point between summer-cold hardy and semi-cold hardy animals - is still reasonably conservative. Likewise, although there is a certain arbitrariness to the assignment of the cold-hardy/winter cold-hardy break point, $-30^{\circ} \mathrm{C}$ seems a sensible marker for delineating animals that show extreme levels of low temperature survival (e.g. continental species and $H$. belgicae). In practice, of course, and depending on the species investigated, some researchers may prefer to collapse the latter two categories into a single "winter cold-hardy" category for statistical purposes - at least until further information is available on the true "winter" cold hardiness of species. Certainly, microhabitat temperatures in the Maritime Antarctic (Fig. 3) suggest that animals with SCPs $<-20^{\circ} \mathrm{C}$ are entirely capable of surviving winter minimum temperatures. Indeed, it may well be that animals with extremely low SCPs are more physiologically noteworthy than they are ecologically distinguishable from the "cold-hardy group". Nonetheless, pending further investigations, for the moment it is sensible to propose the possibility of a "lower group".

\section{Comparison of traditional and ecologically realistic modal analysis}

The proportions of animals expected to be at risk from low summer temperatures - "high group" and summer cold-hardy animals, respectively, according to traditional and "ecologically realistic" modal analysis - were compared for each SCP distribution using a one-tailed paired t-test. (The "ecologically realistic" method of analysis, by definition, decreases the number of animals said to be at risk from low summer temperatures - ie. only one tail of the distributions was affected ).

\section{RESULTS}

Table 1 compares the breakdown of SCP distributions for the five species according to the "traditional" and "ecologically realistic" methods of analysis, respectively. According to the binary model of cold hardiness ("winter" or "summer" modes) the arthropods would, with the exception of the March samples of C. antarcticus and H. belgicae, be described as expressing the "summer" mode. The implication would be that they would all be at risk from sub-zero temperatures. Table 2 compares the proportion of animals at risk from low summer temperatures according to the two methods of analysis. Estimations of the numbers of animals at risk vary little for the two extensively studied species, $C$. antarcticus and $A$. antarcticus, but are clearly different for the other species - exemplified most dramatically by the $53 \%$ difference found between methods for the sample of $H$. belgicae taken on February 5, 2005. Differences between the two assessments of risk are significant $(\mathrm{n}=7 ; t=2.34 ; P=$ 0.029 ) as the proportion "actually" at risk is considerably reduced when SCPs are considered within ecologically realistic thermal thresholds.

\section{DISCUSSION}

Ecologically realistic analysis of the risk of low temperatures to terrestrial arthropods in the Antarctic summer suggests that although they may not have winter levels of cold hardiness, estimates of the threat of low temperature mortality are significantly reduced when the possibility of "semi-cold hardiness" is recognised. That these differences are particularly evident in the species which have received less attention, gives further credence to the observation that the "model" bimodal response is by no means universal in species sharing the same habitats. The broad agreement between estimates of risk for $C$. antarc- 
TABLE 2. Comparison of the proportions of animals at risk from low summer temperatures as determined by traditional modal divisions and ecologically realistic modal divisions.

\begin{tabular}{|c|c|c|c|c|}
\hline \multirow[b]{2}{*}{ Species } & \multirow[b]{2}{*}{ Acclimation treatment* } & \multirow[b]{2}{*}{$\mathrm{n}$} & \multicolumn{2}{|c|}{ Proportion at risk from low summer temperatures $(\%)$} \\
\hline & & & $\begin{array}{c}\text { Traditional modal } \\
\text { division }\end{array}$ & $\begin{array}{l}\text { Ecologically realistic } \\
\text { modal division }\end{array}$ \\
\hline \multicolumn{5}{|l|}{ Collembola } \\
\hline \multirow[t]{2}{*}{ Cryptopygus antarcticus } & $5^{\circ} \mathrm{C} 21$ days on sieved moss & 100 & 99 & 98 \\
\hline & $F(3 / 3 / 05)$ from moss & 128 & 51 & 46 \\
\hline Friesia grisea & $\mathrm{F}(5 / 2 / 05)$ from under rocks & 20 & 65 & 40 \\
\hline \multicolumn{5}{|l|}{ ACARI } \\
\hline Alaskozetes antarcticus & $\mathrm{F}(7 / 2 / 05)$ & 18 & 55 & 55 \\
\hline \multirow[t]{2}{*}{ Halozetes belgicae } & $\mathrm{F}(5 / 2 / 05)$ from lichen-encrusted stones & 23 & 74 & 21 \\
\hline & F (28/3/05) from lichen-encrusted stones & 27 & 11 & 3 \\
\hline Stereotydeus villosus & $5^{\circ} \mathrm{C} 7$ days on moss & 18 & 94 & 66 \\
\hline
\end{tabular}

$* \mathrm{~F}=$ field-fresh.

ticus and $A$. antarcticus lends further support to the large published literature on the distinctly bimodal character of SCPs in these two species, while also suggesting that the two methods of analysis are compatible. However, although the differences between the proportions of animals at risk from low summer temperatures is small, the employment of ecological realistic categories even with these animals, can be informative: the 16 animals that are "semi-cold hardy" in the sample from March 3, 2005, for example, are suggestive of a transitional state coincident with cooling (pre-winter) (Fig. 3a) microhabitat temperatures. Indeed, higher resolution temporal sampling of the shifts between high and low groups in $C$. antarcticus (unpubl. data) suggests that they too show evidence of a "transitional" modality.

In addition to relating SCPs to the risk of freeze mortality, the transitional state offers a means of observing the time course of cold hardening in field or laboratory subjects and pin-pointing the cues, both temporal and physiological, required to bring about cold hardening. Salt (1970) and Powell (1976), for example, have emphasised the role of nucleator abundance in the determination of modal groups. Indeed, using the transitional mode as a key to identifying nucleator management (or other physiological changes) may allow more subtle characterisation of the hardening process, in terms of both process and mechanism.

Although the notion of "ecologically realistic modalities" in SCPs has been illustrated with regard to Antarctic terrestrial arthropods, the approach is applicable to any other species for which the SCP has heuristic relevance (e.g. Sjursen \& Sømme, 2000; Koch et al., 2004). Likewise the cold hardiness of certain life stages of arthropods which otherwise show evidence of prefreeze mortality may also be measured with SCPs - e.g. eggs (Strathdee et al., 1995) or overwintering stages (Turnock \& Fields, 2005) (who are more likely to "supercool"). Determination of the temperature thresholds used to discriminate modalities is, of course, habitat-specific, but the principle of applying conservative thresholds to separate animals "at risk" from animals that are sufficiently cold hardened (or contain less ice nucleating agents), is widely applicable. Indeed, threshold values have been employed in a revealing manner with LLT data in a number of insect cold tolerance studies (e.g. Bale, 1991; Sinclair, 2001) and with the SCPs of some overwintering insects (e.g. Green, 1962; Sullivan, 1965; Tenow \& Nilson, 1990; Turnock \& Fields, 2005). The approach is also transferable to micro-modelling of mortality risk (cf. Sinclair et al., 2006) - e.g. the correlation of SCP distributions from specific time periods (e.g. days, weeks) with temperature thresholds and cooling rates from those periods.

In conclusion, ecological determination of modal points in freezing temperatures enables investigators to ask not just whether animals are cold hardy at seasonal scales, but also whether they are cold hardy within the context of the temperatures they are experiencing at any point in time. This is useful in the context of identifying temporal components of the cold hardening response (e.g. diurnal, summer and pre-winter levels of cold hardiness), as well as for relating exogenous factors like diet and moisture to ecologically realistic low temperature capabilities. The approach preserves the overall patterns of traditional modal analysis but is applicable to any modal distribution of SCPs (i.e. any species), recognises and allows for the inclusion of transitional states and stochastic variability, and above all, provides a considerably more realistic assessment of a given sample's susceptibility to low temperature mortality. In particular, the explicit recognition and characterisation of the "semi-cold-hardy" state may hold clues to deciphering the mechanisms by which arthropods shift their nucleation temperatures. Indeed, the notion of a "transitional" state may also have relevance to investigations of cold hardening and lower lethal temperature in species that are chill-susceptible.

ACKNOWLEDGEMENTS. TCH is supported by a BBSRC studentship. The NERC Antarctic Funding Initiative (CGS6/13) funded fieldwork at Rothera Research Station. Professors L. Sømme and P. Vernon are thanked for their constructive criticism of the manuscript. 


\section{REFERENCES}

Addo-Bediako A., Chown S.L. \& Gaston K.J. 2000: Thermal tolerance, climatic variability and latitude. Proc. $R$. Soc. London (B) 267: 739-745.

BALE J.S. 1987: Insect cold hardiness: freezing and supercooling - an ecophysiological perspective. J. Insect Physiol. 33: 899-908.

BALE J.S. 1991: Implications of cold hardiness for pest management. In Lee R.E. \& Denlinger D.L. (eds): Insects at Low Temperature. Chapman \& Hall, London, pp. 461-498.

BALE J.S. 1993: Classes of insect cold hardiness. Funct. Ecol. 7: 751-753.

BALE J.S. 1996: Insect cold hardiness: a matter of life and death. Eur. J. Entomol. 93: 369-382.

Bale J.S., Worland M.R. \& Block W. 2001: Effects of summer frost exposures on the cold tolerance strategy of a subAntarctic beetle. J. Insect Physiol. 47: 1161-1167.

BLock W. 1994: Differential scanning calorimetry in ecophysiological research. Acta Oecol. 15: 13-22.

Block W. \& Søмme L. 1982: Cold hardiness of terrestrial mites at Signy Island, maritime Antarctic. Oikos 38: 157-167.

Brown C.L., Bale J.S. \& Walter K.F.A. 2004: Freezing induces a loss of freeze tolerance in an overwintering insect. Proc. R. Soc. London (B) 271: 1507-1511.

CANNON R.J.C. 1983: Experimental studies on supercooling in two Antarctic micro-arthropods. J. Insect Physiol. 29: 617-624.

Cannon R.J.C. \& Block W. 1988: Cold tolerance of microarthropods. Biol. Rev. 63: 23-77.

CANNON R.J.C. \& SCHENKer R. 1985: Cold tolerance of a cryptostigmatid mite at Signy Island, Maritime Antarctic. Br. Antarct. Surv. Bul. 67:1-5.

Colmoun E.H. 1960: Acclimation to cold in insects. Entomol. Exp. Appl. 3: 27-37.

CONVEy P. \& Worland M.R. 2000: Refining the risk of freezing mortality for Antarctic terrestrial microarthropods. CryoLetters 21: 333-338

Coulson S.J., LeinaAs H.P., Ims R.A. \& SoviK G. 2000: Experimental manipulation of the winter surface ice layer: the effects on a High Arctic soil microarthropod community. Ecography 23: 299-306.

Green G. W. 1962: Low winter temperatures and the European pine shoot moth, Rhyacionia buoliana (Schiff.) in Ontario. Can. Entomol. 94: 314-336.

Hawes T.C., Bale J.S. \& Worland M.R. (in press a): Moulting reduces freeze susceptibility in the Antarctic mite, Alaskozetes antarcticus. Physiol. Entomol.

Hawes T.C., Couldridge C.E., Bale J.S. \& Worland M.R. (in press b): Habitat temperature and the temporal scaling of cold hardening in the High Arctic collembolan, Hypograstrura tullbergi (Schäffer). Ecol. Entomol.

Koch R.L., Carillo M.A., Venette R.C., Cannon C.A. \& Hutchinson W.D. 2004: Cold hardiness of the multicoloured Asian lady beetle (Coleoptera: Coccinellidae). Environ. Entomol. 33: 815-822.

Powell W. 1976: Supercooling temperature distribution curves as possible indicators of aphid food quality. J. Insect Physiol. 22: $595-599$.

Pryor M.E. 1962: Some environmental features of Hallett Station, Antarctica, with special reference to soil arthropods. Pac. Insects 4: 681-728.
Rothery P. \& BLock W. 1992: Characterising supercooling point distributions. Cryo-Letters 13: 193-198.

Salt R.W. 1936: Studies on the Freezing Process in Insects. Technical Bulletin 116. University of Minnesota, Agricultural Experiment Station, St. Paul, 41 pp.

SALt R.W. 1950: Time as a factor in the freezing of undercooled insects. Can. J. Res. 28: 285-291.

Salt R.W. 1961: Principles of insect cold-hardiness. Annu. Rev. Entomol. 6: 55-74.

SALT R.W. 1970: Analysis of insect freezing temperature distributions. Can. J. Zool. 48: 663-666.

SinCLAIR B.J. 2001: Field ecology of freeze tolerance: interannual variation in cooling rates, freeze-thaw and thermal stress in the microhabitat of the alpine cockroach Celatoblatta quinquemaculata. Oikos 93: 286-293.

Sinclair B.J., Klok C.J., Scott M.B., Terblanche J.S. \& Chown S.L. 2003: Diurnal variation in supercooling points of three species of Collembola from Cape Hallett, Antarctica. $J$. Insect Physiol. 49: 1049-1061.

Sinclair B.J., Terblanche J.S., Scott M.B., Blatch G.L., KloK C.J. \& Chown S.L. 2006: Environmental physiology of three species of Collembola at Cape Hallett, North Victoria Land, Antarctica. J. Insect Physiol. 52: 29-50.

Sudrsen H. \& Sømme L. 2000: Seasonal change in tolerance to cold and desiccation in Phauloppia sp. (Acari, Oribatida) from Finse, Norway. J. Insect Physiol. 46: 1387-1396.

Søмme L. 2000: The history of cold hardiness research in terrestrial arthropods. Cryo-Letters 21: 289-296.

Sømme L. \& B Bock W. 1982: Cold hardiness of Collembola at Signy Island, maritime Antarctic. Oikos 38: 168-176.

Strathdee A.T., Howling G.G. \& Bale J.S. 1995: Cold hardiness of overwintering aphid eggs. J. Insect Physiol. 41: 653-657.

SulLivan C.R. 1965: Laboratory and field investigations on the ability of eggs of the European pine sawfly, Neodiprion sertifer (Geoffroy) to withstand low temperatures. Can. Entomol. 97: 978-993.

Tenow O. \& Nilssen A. 1990: Egg cold hardiness and topoclimatic limitations to outbreaks of Epirrita autumnata in northern Fennoscandia. J. Appl. Ecol. 27: 723-734.

Turnock W.J. \& Fields P.G. 2005: Winter climates and cold hardiness in terrestrial insects. Eur. J. Entomol. 102: 561-576.

WORLAND M.R. 2005: Factors that influence the supercooling point of the sub-Antarctic springtail Tullbergia antarctica. $J$. Insect Physiol. 51: 881-894.

Worland M.R. \& Block W. 2003: Desiccation stress at subzero temperatures in polar terrestrial arthropods. J. Insect Physiol. 49: 193-203.

Worland M.R. \& Convey P. 2001: Rapid cold hardening in Antarctic microarthropods. Funct. Ecol. 15: 515-524.

Worland M.R. \& LuKešoví A. 2000: The effect of feeding on specific soil algae on the cold hardiness of two terrestrial Antarctic micro-arthropods (Alaskozetes antarcticus and Cryptopygus antarcticus). Polar Biol. 23: 766-774.

Young S.R. \& BLOCK W. 1980: Experimental studies of cold tolerance in an Antarctic terrestrial mite. J. Insect Physiol. 26: 189-200.

Zar J.H. 1999: Biostatistical Analysis. 4th ed. Prentice Hall, Upper Saddle River, NJ, 663 pp.

Received January 18, 2006; revised and accepted June 30, 2006 